\title{
The Role of the Internal Heat Gains for Artificial Lighting on the Energy Performance of Buildings
}

\author{
Guglielmina Mutani ${ }^{1 *}$, Edoardo De Nicolò ${ }^{1}$, Laura Blaso ${ }^{2}$, Simonetta Fumagalli $^{2}$, Antonella Tundo $^{3}$ \\ ${ }^{1}$ R3C, Department of Energy, Politecnico di Torino, c.so Duca degli Abruzzi, 24, Torino 10129, Italy \\ ${ }^{2}$ ENEA Smart Cities and Communities Laboratory, Smart Energy Division, Department of Energy Technologies and Renewable \\ Sources - via Enrico Fermi, at JRC, 2749, Ispra (VA) 21027, Italy \\ ${ }^{3}$ ENEA Smart Cities and Communities Laboratory, Smart Energy Division, Department of Energy Technologies and \\ Renewable Sources - via Giulio Petroni, 15 f, Bari 70124, Italy
}

Corresponding Author Email: gugliemina.mutani@polito.it

https://doi.org/10.18280/ijht.390501

Received: 17 July 2021

Accepted: 22 October 2021

\section{Keywords:}

LENI, artificial lighting, energy performance indicator, energy certification, heat gains, light control systems, $n Z E B$, smart buildings

\begin{abstract}
This paper aims to propose a procedure for calculating the energy performance indexes of buildings considering the seasonality of internal gains due to artificial lighting with a monthly quasi-steady-state energy balance. The proposed methodology evaluates the heat gains due to the integrated natural-artificial lighting system with the Lighting Energy Numerical Indicator (LENI). For the evaluation of buildings' global energy performance and for some energy services, this contribution cannot be considered constant annually as depend strongly by climate conditions. The effect of daylighting, type of light sourcesluminaires, building orientation and shading devices could influence lighting contribution of the internal heat gains. Then, the proposed methodology evaluates the internal heat gains with monthly energy balances. This methodology was applied to the case study of the "Brancaccio" retirement home in Matera (IT) for which the values of the energy performance indexes were compared with the standard normative approach using constant internal heat gains. The results of this work underline the importance of performing a detailed analysis that considers the availability of natural light in the different months of the year, the efficiency of the different lighting systems and their power installed per unit of area as a function of the lighting comfort requirements in the different types of environments.
\end{abstract}

\section{INTRODUCTION}

The energy consumption of buildings has a strong environmental impact and has been widely debated and constantly a developing topic. The European Union has issued a series of specific directives that require the verification of the energy performance of all buildings (existing and new construction) in terms of global consumption, with limit values not to be exceeded. Electrical energy covered an important quota of final energy consumption and lighting can be a significant part of this electrical consumption, especially in residential buildings [1].

In Italy, the Ministerial Decree of 26/06/2015, which entered into force on October $1^{\text {st }} 2015$, introduced important innovations regarding energy efficiency and low-carbon technologies. Among these, the energy class of buildings must be assessed in terms of non-renewable primary energy through the global non-renewable energy performance index $\mathrm{EP}_{\mathrm{gl}, \mathrm{nren}}$ as the sum of the non-renewable energy indexes for each energy service $[2,3]$ :

$$
\mathrm{EP}_{\mathrm{gl}, \text { nren }}=\mathrm{EP}_{\mathrm{H}, \text { nren }}+\mathrm{EP}_{\mathrm{C} \text {,nren }}+\mathrm{EP}_{\mathrm{W} \text {,nren }}+\mathrm{EP}_{\mathrm{V} \text {,nren }}+\mathrm{EP}_{\mathrm{T} \text {,nren }}+\mathrm{EP}_{\mathrm{L} \text {,nren }}
$$

This energy performance index EP is expressed in $\mathrm{kWh} / \mathrm{m}^{2} /$ year so as to consider only the level of energy efficiency of the building and not its size. It takes into account the non-renewable primary energy requirement for all energy services in a building: space heating and cooling $\left(\mathrm{EP}_{\mathrm{H}, \mathrm{nren}}\right.$ and $\left.\mathrm{EP}_{\mathrm{C}, \text { nren }}\right)$, hot water production $\left(\mathrm{EP}_{\mathrm{W}, \mathrm{nren}}\right)$, ventilation $\left(\mathrm{EP}_{\mathrm{V}, \text { nren }}\right)$, and, for non-residential sectors, transport of people or things $\left(\mathrm{EP}_{\mathrm{T}, \mathrm{nren}}\right)$ and artificial lighting $\left(\mathrm{EP}_{\mathrm{L}, \mathrm{nren}}\right)$.

The annual energy performance indicator $\mathrm{EP}_{\mathrm{gl}, \mathrm{nren}}$ is also used to classify the buildings with an energy performance certification $[4,5]$ and the $\mathrm{EP}_{\mathrm{gl}, \text { nren }}$ is therefore calculated through methodologies codified by technical standards and national legislation, in transposition of European directives.

The "family" of UNI/TS 11300 Technical Standards was created with the aim of defining a unique calculation methodology for determining the energy performance of buildings with a monthly quasi-steady-state calculation method. In these six Standards, the internal heat gains, due to people, electrical equipment and lighting systems, are evaluated through a constant annual average value depending on the type of user. In this work, this approach is investigated in particular with regard to the role played by heat gains due to the lighting system [6]. The use of a standardized average value [7] does not consider crucial factors such as the differences in: the availability of natural light in the various months of the year and for different climates [8], the effect of shading devices, the efficiency of the lighting systems and the electrical power installed per unit of surface area as a function of the lighting comfort requirements in the different 
environments. The calculation of internal heat gains for lighting must, therefore, be approached with greater precision, since it can contribute significantly to the final energy performance of a building.

Moreover, in Eq. (1) the different contributions (heating, cooling, hot water production, ventilation, transport and lighting) can be considered separately, evaluating the mutual influence on the global non-renewable energy performance index $\mathrm{EP}_{\mathrm{gl}, \text { nren. }}$. For example, the use of inefficient light sources results in a greater contribution of thermal energy to the environment, which translates into a decrease in energy consumed for space heating $\left(\mathrm{EP}_{\mathrm{H}}\right)$, a greater consumption of energy for space cooling $\left(\mathrm{EP}_{\mathrm{C}}\right)$ and an increase of the consumption of the lighting system $\left(\mathrm{EP}_{\mathrm{L}}\right)$.

The analysis conducted in this work starts from previous research about the investigation of the lighting system on the energy performance of an office building [9]. Further research will analyze the effect of various lighting systems on the energy performance of buildings with an hourly time step [10].

The description of the methodology used in this work is explained in Section 2, the case study is presented in Section 3 and the results are discussed in Section 4.

\section{MATERIALS AND METHODS}

The proposed work aims to identify a new procedure for the calculation of internal heat gains related to the integrated natural-artificial lighting system for the calculation of the energy performance of buildings. Moreover, for a case study, a comparison of the energy performance indexes that are obtained through the two different approaches: with constant internal heat gains and with a monthly variation due to influence of the lighting system, as suggested by the authors.

The calculation of energy performance indicators is carried out, in both cases, according to the monthly quasi-steady-state calculation method of the technical standards UNI/TS 11300; only the evaluation of internal heat gains follows two different paths.

If the above-mentioned standards consider the total internal heat gains with a constant annual average value (e.g. $6 \mathrm{~W} / \mathrm{m}^{2}$ for office buildings and $8 \mathrm{~W} / \mathrm{m}^{2}$ for buildings used as hospitals, retirement homes and similar), the proposed procedure evaluates separately the contribution of internal heat gains for lighting and then adds it to the other contributions related to the occupation and use of electrical appliances. In particular, the heat gains for lighting are calculated on the basis of energy efficiency of the lighting system, evaluated with the Lighting Energy Numerical Indicator (LENI) according to the European Standards EN 15193-1:2017 [11] (in Italy: UNI EN 151931:2017, "Energy performance of buildings - Energy requirements for lighting - Part 1").

The LENI index represents the energy consumption of lighting equipment that is equal to the energy delivered to the building neglecting the losses of the distribution system inside the building. The primary energy index $\mathrm{EP}_{\mathrm{L}}$ can be obtained multiplying the delivered energy by the primary energy factors for electricity: $f_{p \text {,ren }}=0.47$ and $f_{p, \text { nren }}=1.95$ [2]. Then, the energy performance for the artificial lighting service is:

$$
\begin{aligned}
\mathrm{EP}_{\mathrm{L}, \text { ren }} & =\mathrm{LENI} \cdot \mathrm{f}_{\mathrm{p} \text {,ren }} \\
\mathrm{EP}_{\mathrm{L}, \text { nren }} & =\mathrm{LENI} \cdot \mathrm{f}_{\mathrm{p} \text {,nren }}
\end{aligned}
$$

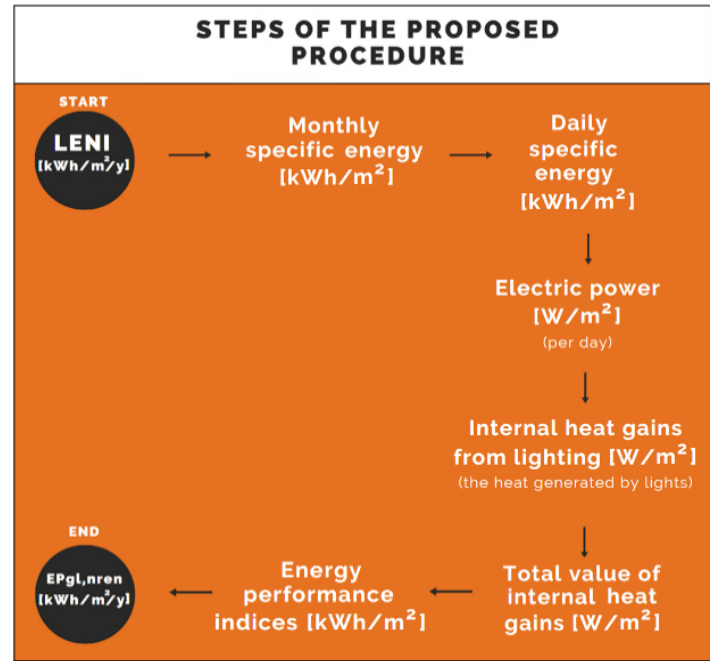

Figure 1. Suggested procedure

The procedure proposed in this article (Figure 1) is structured in the following steps:

1. The energy required for artificial lighting is calculated through the LENI index. The calculation was performed using the LENICALC software (version 3) developed by ENEA [12, 13]. In this work, LENI was calculated with Method 1, named Comprehensive Method; for each room or zone, the calculation of the daylight dependency factor $F_{D}$, occupancy dependency factor $F_{O}$, constant illuminance factor $F_{c}$ and many other variables is required. These time-consuming intermediate calculations are required to obtain the LENIsub for zone, room, and floor. Figure 2 shows the flow diagram of Method 1 of EN 15193-1:2017 where all factors and input data, required for the calculation, are shown.

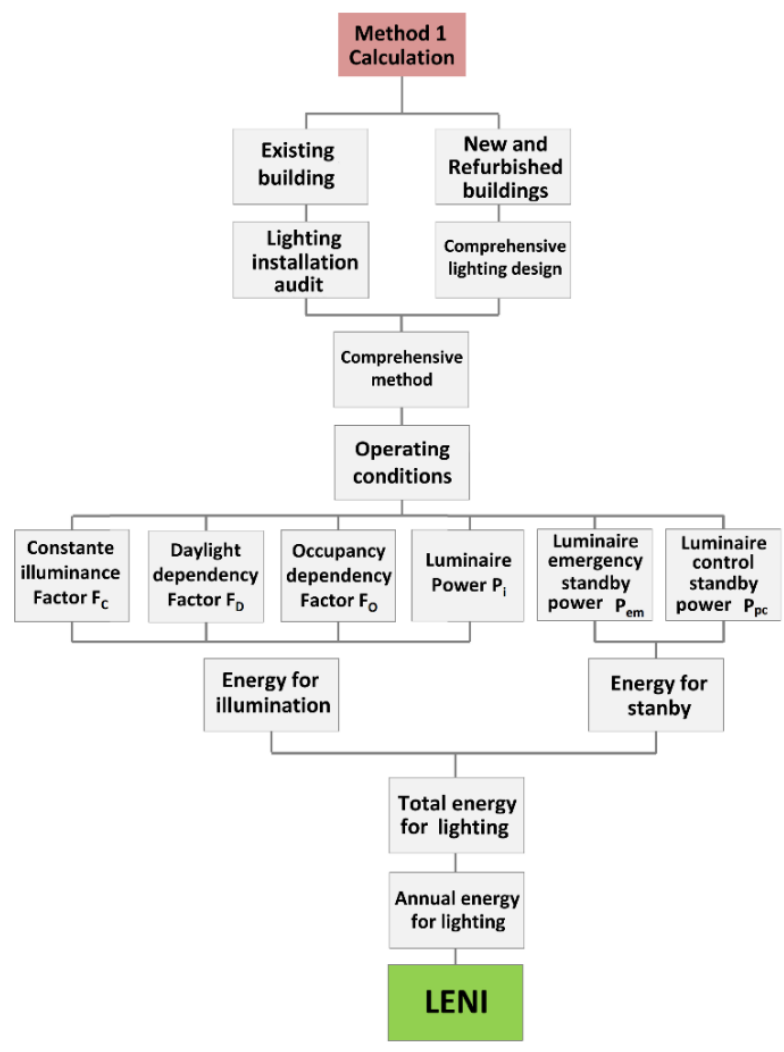

Figure 2. Flow diagram of Method 1: EN 15193-1:2017 
2. For every value of annual LENI, monthly specific energy for lighting $\left(\mathrm{kWh} / \mathrm{m}^{2}\right)$ have been calculated, considering the monthly values during both the heating and cooling seasons.

3. Daily specific energy for lighting is obtained dividing the monthly energy by number of days of the month $\left(\mathrm{kWh} / \mathrm{m}^{2}\right)$.

4. Daily specific power $\left(\mathrm{W} / \mathrm{m}^{2}\right)$ is obtained dividing the specific daily energy $\left(\mathrm{kWh} / \mathrm{m}^{2}\right)$ by the $24 \mathrm{~h}$ and multiplying for 1000 (conversion into watt).

5. The amount of heat released into the room by the lighting sources and luminaires, as internal heat sources, has been identified. Starting from literature data, the $79 \%$ for fluorescent and the $75 \%$ for LED lighting sources of the electrical power (calculated in point 4) was assumed as thermal energy flux losses into the environment. These values were published by the Department of Energy of the United States government (DOE) as part of a study on the efficiency of the various lighting technologies and are also reported in a lighting manual [14].

6. The contribution of heat gains due to the presence of people is obtained as a function of the density of occupancy in the different environments from Italian UNI/TS 11300-1 (in chapter 13.1.2 table 16 [6]).

7. The value of heat gains due to electrical equipment is obtained according to the building category from Italian UNI/TS 11300-1 (in chapter 13.1.2 table 17 [6]).

8. Finally, the total value of the internal heat gains has been calculated as the sum of the internal contributions due to lighting (point 5), occupancy (point 6) and use of electrical equipment (point 7).

9. The value determined for the total heat gains has been used to calculate the energy performance indices for the case study under examination. In particular, the monthly and annual values of the indices (EPH, EPc, EPw, EPv, $\mathbf{E P}_{\mathbf{T}}$ e $\left.\mathbf{E P}_{\mathbf{L}}\right)_{n, \text { ren }}$ were calculated using the heat inputs evaluated with the two methods:

a. Normative (standard average annual value);

b. Proposed by the authors (comprehensive/ monthly calculation).

10. The energy performance index for lighting has been calculated using Eq. (3).

11. Finally, the global non-renewable energy performance index $\mathbf{E} \mathbf{P}_{\text {gl,nren }}$ and the corresponding energy class of the building have been calculated.

12. The results obtained with the different calculation procedures for internal heat gains have been compared (paragraph 4.3).

The calculation on a monthly basis is of very important, because it helps to understand how the energy performance index for lighting affects the total energy consumption of a building. While the internal heat gains related to the occupants and electrical equipment do not undergo substantial variations over the months, the internal heat contribution due to lighting strongly depends on the availability of daylight in the different months of the year and therefore requires to be calculated through a more detailed procedure considering the monthly and seasonal variations of the integrated natural-artificial lighting system.

\subsection{Heat emitted by lighting sources}

Before using the literature values (point 5) a more in-depth study was performed to estimate the amount of thermal energy released into the environment by the entire light sourceluminaire-control lighting system.

In laboratory tests, a spectroradiometer coupled with an integrating sphere has been used, providing both photometric and radiometric values on the test surface and in particular luminance $\mathrm{Lv}\left[\mathrm{cd} / \mathrm{m}^{2}\right.$ or $\left.1 \mathrm{~m} /\left(\mathrm{sr} \mathrm{m}^{2}\right)\right]$ and radiance Le $[\mathrm{W} /(\mathrm{sr}$ $\left.\mathrm{m}^{2}\right)$ ]. From these measures it emerged that the ratio:

$$
\frac{L v}{L e}=\frac{d^{2} \Phi /(d A \cdot \cos \theta \cdot d \Omega)}{d^{2} P /(d A \cdot \cos \theta \cdot d \Omega)}=\frac{\text { luminous flux }}{\text { radiant power }}
$$

remains almost constant in relation to the lighting technology (e.g. $335 \mathrm{~lm} / \mathrm{W}$ for LED sources and $310 \mathrm{~lm} / \mathrm{W}$ for fluorescent sources). The type of spectrum is in fact characteristic of each technology with a specific correlated colour temperature (CCT).

Given Lv/Le value and remembering that the luminous flux is the radiant power weighted by the sensitivity of the human eye to light, it was possible to proceed as follows in energetic terms:

- The radiant power of the sources under examination was calculated from the relation (4), using the inverse formula.

- The amount of energy not useful for lighting (i.e. Not Lighting Energy NLE) was derived from the difference between the electrical power and the radiant power.

- The percentage of light emitted by the luminaire was calculated utilizing the ratio between the radiant power and the electrical absorbed power (i.e. the luminous efficiency of lighting source and luminaire)

- The percentage corresponding to everything that is not light has been calculated from the ratio between the NLE and the electrical absorbed power.

For LED sources, everything that is not light has been considered heat (the spectrum of LEDs is almost entirely in the visible). Then, considering the presence of the electrical transformer, the amount of heat emitted into the environment by the LED luminaires examined can be approximately estimated as the $60 \%$ of the supplied electrical power.

Fluorescent light sources emit some electromagnetic radiation also in the wavelengths of infrared (IR) and ultraviolet (UV) spectrum range. In this analysis, the UV quota has been neglected, for simplicity.

There is still the problem, at luminaire level, to split the NLE amount into light trapped within the luminaire (e.g. internal reflections) and heat released to the environment.

For this reason, it has been decided to utilize literature values [12], limited only to the light source, not the whole light source-luminaire-control lighting system.

\section{CASE STUDY "BRANCACCIO"}

The case study is the "Brancaccio" retirement home in Matera (in South Italy at a latitude: $40.7^{\circ} \mathrm{N}$ ). The structure, dating back to the $1970 \mathrm{~s}$, covers approximately $7500 \mathrm{~m}^{2}$ (on 5 levels) and can accommodate 250 guests including elderly people and health workers. The hospital rooms are distributed on the last three floors of the residence, with differences in relation to the degree of self-sufficiency and the needs of the patients. In the first two levels of the structure there are the common rooms of the "multifunctional center" and the offices 
of the "Fondazione Brancaccio", the "Il Sicomoro" group and the non-profit association "Amici del cuore". Figure 3 shows a three-dimensional (3D) view of the case study and of surrounding buildings (obstructions). The type of structure and the surrounding elements can influence heat dispersions and solar heat gains. About the building structure, in Table 1 the thermal transmittances assumed for the envelope are shown.

Table 1. Building envelope components characteristics

\begin{tabular}{cc}
\hline Envelope element & $\begin{array}{c}\text { Thermal Transmittance } \\
{\left[\mathbf{W} / \mathbf{m}^{2} / \mathbf{K}\right]}\end{array}$ \\
\hline Vertical wall & 1.14 \\
Lower slab (dispersing towards & 1.69 \\
the ground) & 1.55 \\
Slab between floors & 1.69 \\
Flat roof & 3.16 \\
Windows
\end{tabular}

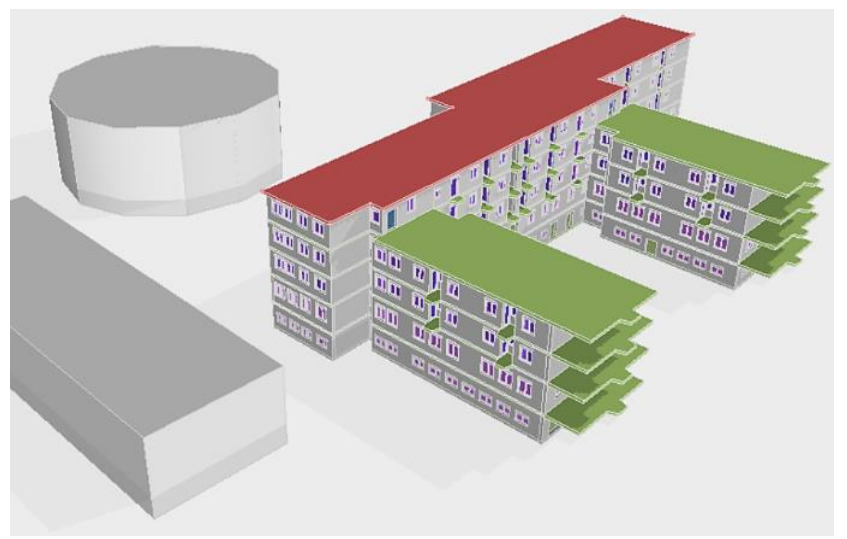

Figure 3. 3D view of Brancaccio and its surrounding spaces

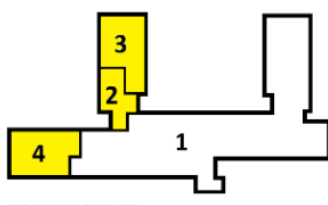

GROUND FLOOR
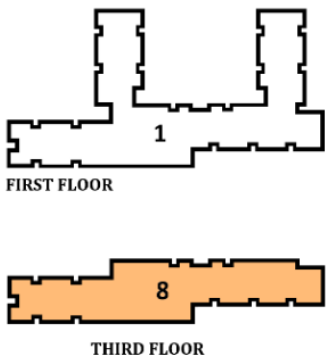

Figure 4. Thermal zones of Brancaccio retirement home

As required by UNI/TS 11300-1, the building has been divided into "thermal zones" (in chapter 7) shown in Figure 4.

The technological systems were installed starting from 2016 following energy retrofit interventions of the entire structure. The thermal power plant that serves most of the building (zone 1 ) is located on the ground floor and includes a hybrid system with condensation boilers and heat pumps, used for space heating services and the production of domestic hot water. In six different rooms (zones 2 to 7), Variable Refrigerant Volume (VRV) systems were installed guaranteeing individual climate control of air conditioning for space heating, cooling and mechanical ventilation. Floor three (zone 8) is served by an independent thermal power plant, located on the terrace of the building, consisting of two gas boilers and a steam compression refrigeration machine.

The solar thermal collectors and the photovoltaic modules, installed on the roof of the retirement home, increase the global efficiency of the systems and reduce the greenhouse gas emissions. There is also a people/things transport service with two elevators.

As it is possible to observe from Figure 5, almost all the rooms in the building can also benefit from daylight, thanks to the presence of numerous windows (double glass with light transmission value $\tau=81 \%$ ). The usable area and the total transparent area are respectively $6495 \mathrm{~m}^{2}$ and $1090 \mathrm{~m}^{2}$.

The lighting fixtures are installed on the ceiling and, for the first four floors, are equipped with LED sources. In the hospital rooms on the last level, there are wall-mounted lighting luminaries, equipped with fluorescent sources. The control systems are all manual ON/OFF with the exception of the corridors (environments without natural light) in which there are control systems based on occupancy, with manual ON/auto OFF type.

The lighting system is sized according to the regulatory minimum requirements, with power density values shown in Table 2. For further confirmation, the average illuminance value of the different environments was calculated with the lighting engineering software Dialux Evo 9.1, obtaining values of approximately 130 lux for the hospital rooms and 200 lux for the bathrooms

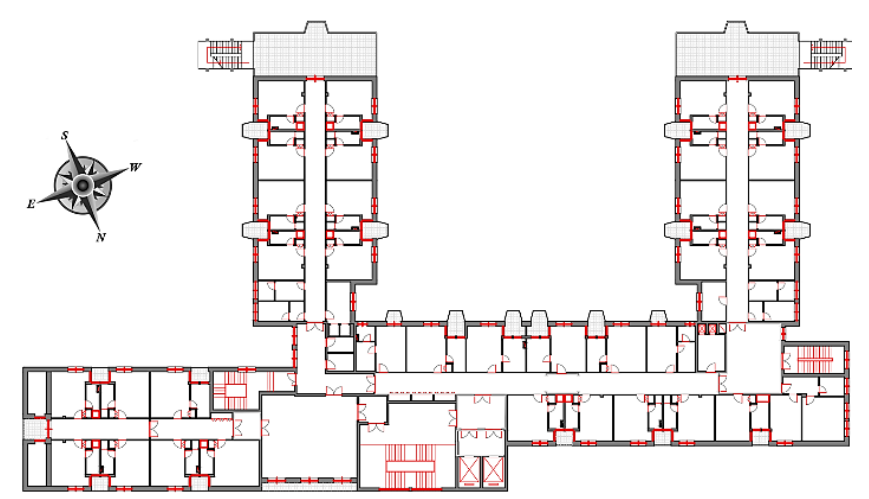

Figure 5. First floor plan (similar to second floor)

Table 2. Installed power density of lighting systems

\begin{tabular}{ccc}
\hline Zone & $\begin{array}{c}\text { Power Density } \\
{\left[\mathbf{W} / \mathbf{m}^{2}\right]}\end{array}$ & $\begin{array}{c}\text { Intended use of the zones } \\
\text { (D.P.R 412/93) }\end{array}$ \\
\hline 1 & 2.7 & E.3. retirement home \\
2 & 5.9 & E.2. offices \\
3 & 6 & E.2. offices and similar \\
4 & 4 & E.6 (2) gym \\
5 & 5.4 & E.1 (3) hotels and guesthouses \\
6 & 4.2 & E.4. recreational activity \\
7 & 5.9 & E.2. offices \\
8 & 7.6 & E.3. retirement home \\
\hline
\end{tabular}

\section{RESULTS AND DISCUSSION}

\subsection{Lighting energy numerical indicator}

The assessment of the energy needs for the lighting of the "Brancaccio" retirement home was performed with the 
LENICALC v. 3 software.

Table 3 shows the values of the LENI index for each floor ("Floor calculation") and the entire building ("Building calculation"). It is possible to observe that the value of the LENI related to the third floor is much higher than that of the other levels; this is due to a higher installed power per unit area and the use of fluorescent lighting sources.

Table 3. LENI index values

\begin{tabular}{cccc}
\hline & $\begin{array}{c}\text { Installed power } \\
{[\mathbf{W}]}\end{array}$ & $\begin{array}{c}\text { Area } \\
{\left[\mathbf{m}^{2}\right]}\end{array}$ & $\begin{array}{c}\text { LENI } \\
{\left[\mathbf{k W h} / \mathbf{m}^{2} / \mathbf{y}\right]}\end{array}$ \\
\hline Ground floor & 4939.8 & 1478 & 13.83 \\
Mezzanine floor & 5707.1 & 1470 & 11.54 \\
First floor & 3667.5 & 1340 & 7.43 \\
Second floor & 3667.5 & 1340 & 7.43 \\
Third floor & 6540.2 & 866 & 30.68 \\
Building & $\mathbf{2 4 5 2 2 . 1}$ & $\mathbf{6 4 9 4}$ & $\mathbf{1 2 . 9 2}$ \\
\hline
\end{tabular}

Table 4. Monthly specific energy for artificial lighting

\begin{tabular}{cccccc}
\hline \multicolumn{6}{c}{ Building monthly specific energy $\left[\mathbf{k W h} / \mathbf{m}^{2} /\right.$ month] } \\
\hline Jan & Feb & Mar & Apr & May & June \\
1.10 & 1.08 & 1.07 & 1.06 & 1.05 & 1.05 \\
July & Aug & Sept & Oct & Nov & Dec \\
1.06 & 1.06 & 1.07 & 1.09 & 1.11 & 1.13 \\
\hline
\end{tabular}

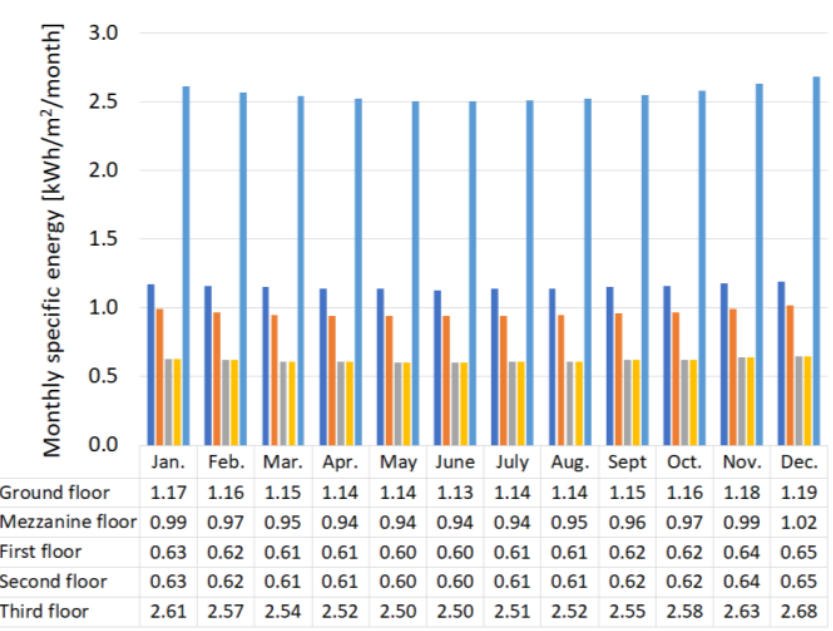

Figure 6. Monthly specific energy per floor $\mathrm{kWh}_{\mathrm{L}} / \mathrm{m}^{2} /$ month

More interesting is the calculation of the monthly specific energy for the lighting service (Table 4, Figure 6). From the analysis of the results, the following consideration can be made:

- The monthly specific energy reaches the highest values in December and the lowest values in June, corresponding to the periods of the year with lower and higher availability of natural light.

The monthly specific energy values for the thermal zones of the case study have been calculated, as the sum of the monthly energy of the individual rooms, and used to calculate the internal lighting contributions according to the procedure proposed in paragraph 2 .

\subsection{Internal heat gains}

As previously mentioned, the value of internal heat gains for the presence of people $\left(\mathrm{W} / \mathrm{m}^{2}\right)$ was calculated as a function of occupancy density (UNI/TS 11300-1, Table 16). To accurately assess this contribution, the actual hours of daily presence were assumed for each environment, based on the typical day of the "Brancaccio" retirement home. In this way, it was possible to consider the influence of various factors such as the time of external visits of relatives and friends, the maximum crowding allowed for each environment and the time spent in the different rooms in relation to the degree of self-sufficiency of the patients.

The internal contributions for the electric appliances are instead calculated, according to the intended use of the environments, through a constant average value (UNI/TS 11300-1, Table 17 [6]).

To these contributions, was then added the internal contributions for artificial lighting, calculated on the basis of the LENI index, according to the procedure in Figure 1. Table 5 shows the annual values of the internal heat gains for the different thermal zones of the case study considering the minimum and maximum lighting monthly contribution. On average, the lighting corresponds to about $19 \%$ but this percentage depends on the zone: highest value of $33 \%$ can be observed for zone 8 in wintertime and lowest value of $11 \%$ for zone 7 in summertime.

While the values of heat gains for the presence of people and electrical appliances are considered constant throughout the year (e.g. retirement home in operation 365 days); those for lighting vary from month to month, depending on the LENI and therefore on the availability of natural light. Consequently, the values shown in Table 5 are to be understood as average annual values, while the third column represents the monthly variation of lighting.

Table 5. Internal heat gains per thermal zone

\begin{tabular}{|c|c|c|}
\hline Zone & фint,occ+el & 申int,lighting (min-max)monthly \\
\hline & {$\left[\mathbf{W} / \mathbf{m}^{2}\right]$} & {$\left[\mathbf{W} / \mathbf{m}^{2}\right]$} \\
\hline 1 & 4.84 & $0.78-0.88$ \\
\hline 2 & 4.63 & $1.22-1.37$ \\
\hline 3 & 5.70 & $2.15-2.42$ \\
\hline 4 & 3.32 & $1.18-1.33$ \\
\hline 5 & 4.24 & $0.67-0.78$ \\
\hline 6 & 3.43 & $0.79-0.92$ \\
\hline 7 & 6.35 & $0.80-0.94$ \\
\hline 8 & 6.25 & $2.65-3.02$ \\
\hline Average* & 4.98 & $1.08-1.23$ \\
\hline
\end{tabular}

Table 6. Percentage variation of lighting contributions during the year

\begin{tabular}{c|c|c|c|c|c|c|c}
\hline \multicolumn{7}{c}{ Thermal Zone } \\
\hline 1 & 2 & 3 & 4 & 5 & 6 & 7 & 8 \\
\hline 1.8 & 2.5 & 3.4 & 3.3 & 2.2 & 3.0 & 1.9 & 4.1 \\
\hline$[(\phi(\max )-\phi(\min )) / \phi($ medium $] \cdot 100$
\end{tabular}

Table 6 shows, for each thermal zone, the percentage variation between the maximum monthly value and the minimum value of total internal contributions:

- The greatest variation is found in thermal zone 8, corresponding to the third floor, where the greater installed power (with fluorescent lighting sources) has a significant impact on the variable share of internal heat input.

- The highest monthly values of the internal heat gains are reached during the winter season, while the 
lowest values are reached during the summer months; these results are in fact consistent with the monthly variation of the LENI index.

\subsection{Energy performance results}

The calculation of the energy performance indexes for the "Brancaccio" retirement home was carried out by considering the two cases shown in Figure 7:

A) Entire building, with total internal heat gains equal to:

- $\quad 6.06 \leq \phi \leq 6.21 \mathrm{~W} / \mathrm{m}^{2}$ - from proposed procedure;

- $\quad 7.7 \mathrm{~W} / \mathrm{m}^{2}$ - from the UNI/TS 11300 technical standard $\left(6 \mathrm{~W} / \mathrm{m}^{2}\right.$ for offices and $8 \mathrm{~W} / \mathrm{m}^{2}$ for retirement homes).

B) Third floor, with total internal heat gains equal to:

- $8.9 \leq \phi \leq 9.27 \mathrm{~W} / \mathrm{m}^{2}$ - from proposed procedure;

- $8 \mathrm{~W} / \mathrm{m}^{2}$ - from the UNI/TS 11300 technical standard (floor three is used entirely as a retirement home).

The low heat gains variation is certainly due to the low installed power of lighting systems.

$\square$ PROPOSED PROCEDURE $\quad \square$ UNI/TS 11300

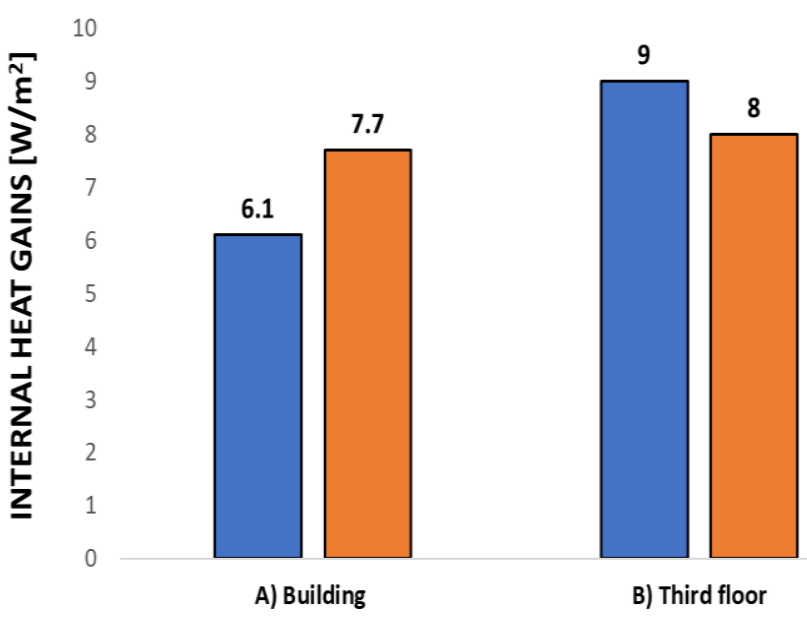

Figure 7. Internal heat gains for occupancy, electrical appliances and lighting systems used

The legislation/standard overestimates the actual value of internal heat gains for case A, while it underestimates them for case B. These discrepancies are attributable to the share of contributions for artificial lighting: if for the entire building the average value of $\phi_{\text {int, }}$ ill is $1.12 \mathrm{~W} / \mathrm{m}^{2}$, for the third floor (with fluorescent lighting sources) this value is $2.74 \mathrm{~W} / \mathrm{m}^{2}$.

In general, it emerges the importance of carrying out a detailed analysis considering the installed power per unit of surface area, the typology of light source-luminaire-control system used and the availability of natural light, in order to evaluate the variation of the energy performance indicators in the different months of the year, concerning the different contribution provided by the variation of internal heat gains.

The calculation of the performance indexes, in terms of nonrenewable primary energy, was therefore carried out on an annual basis and, for the proposed procedure, also on a monthly basis. The differences found between the two methodologies concern the non-renewable primary energy for space heating and cooling $\left(\mathrm{EP}_{\mathrm{H}, \text { nren }}\right.$ ed $\left.\mathrm{EP}_{\mathrm{C}, \mathrm{nren}}\right)$, that depend also on the value of the internal heat gains. The value of the lighting energy performance index $\mathrm{EP}_{\mathrm{L}, \text { nren }}$ varies concerning the LENI index and is therefore very different in the two cases considered depending on lighting technology used.

Figures 8 and 9 show the annual values of the nonrenewable primary energy requirement respectively for space heating and cooling, domestic hot water production and lighting services, as well as the value of the global energy performance index $\mathrm{EP}_{\mathrm{gl}, \mathrm{nren}}$ (in this work, the primary energy for transport and ventilation was also evaluated, although not graphed).

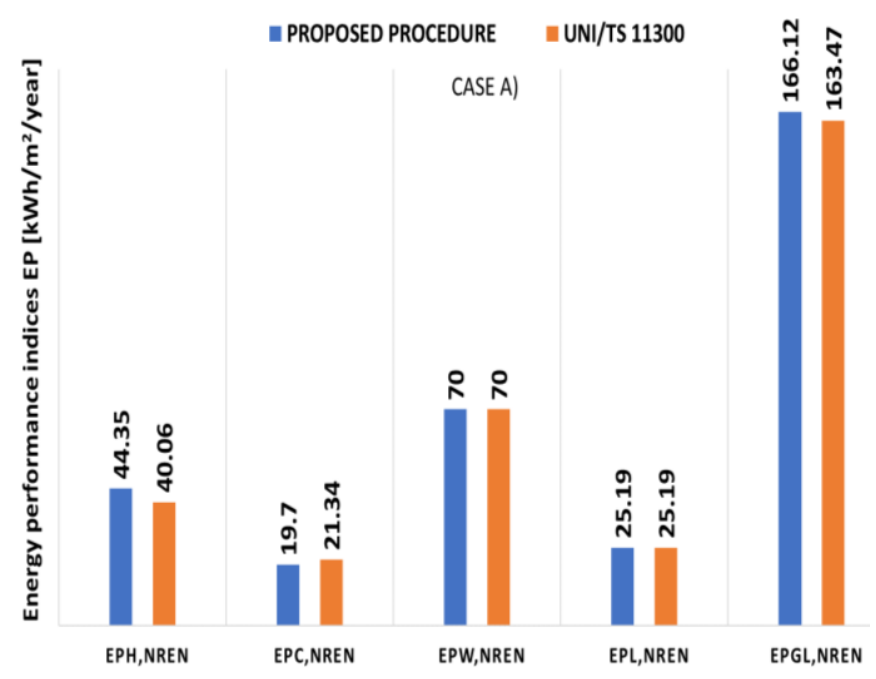

Figure 8. $\mathrm{EP}_{\mathrm{n}, \text { ren }}$ indexes for retirement home, case $\mathrm{A}$

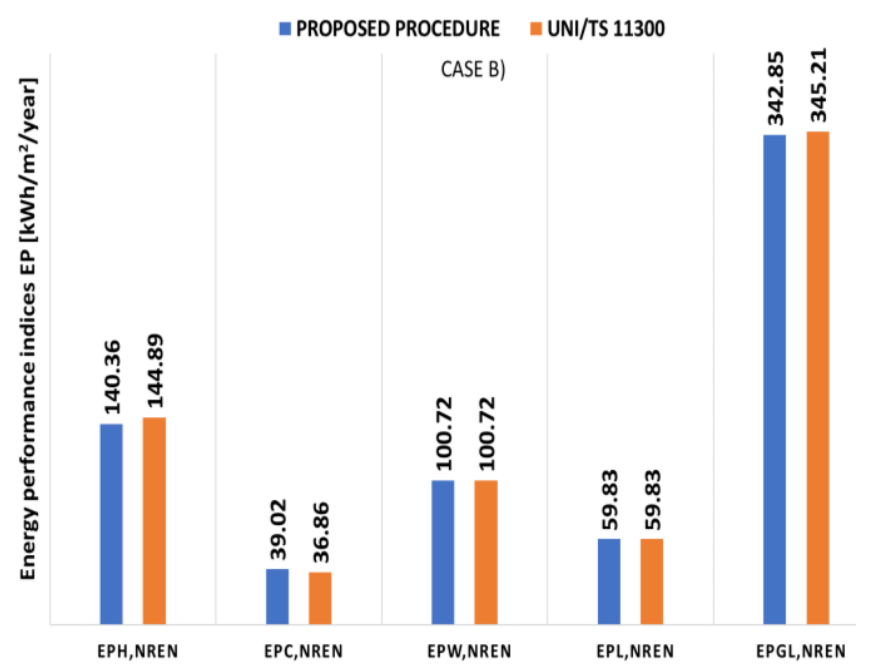

Figure 9. $\mathrm{EP}_{\mathrm{n}, \mathrm{ren}}$ indexes for retirement home, case $\mathrm{B}$

The non-renewable energy performance index for lighting was calculated, in both cases, multiplying the LENI value by the non-renewable conversion factor of electricity (i.e. $\mathrm{f}_{\mathrm{p}, \text { nren }}=$ 1.95 in equation 3 ) to obtain the primary energy.

Using the normative approach leads to differences compared to the proposed procedure, both in terms of overall and single-service consumption.

The value of the $\mathrm{EP}_{\mathrm{gl}, \text { nren }}$ index varies in relation to the energy indicators for space heating and cooling $\left(\mathrm{EP}_{\mathrm{H}, \mathrm{nren}}\right.$ and $\mathrm{EP}_{\mathrm{C}, \mathrm{nren}}$ ), which in turn depend on the contribution of internal heat gains: higher internal heat gains means lower $\mathrm{EP}_{\mathrm{H}, \mathrm{nren}}$, higher $\mathrm{EP}_{\mathrm{C} \text {,nren }}$ and, overall, a slightly lower $\mathrm{EP}_{\mathrm{gl} \text {,nren }}$. Conversely, lower internal heat gains means higher EPH,nren and lower $\mathrm{EP}_{\mathrm{C}, \mathrm{nren}}$ 
In both cases, the $\mathrm{EP}_{\mathrm{gl}, \mathrm{nren}}$ value varies little between the two procedures, because the increase or decrease of the $\mathrm{EP}_{\mathrm{H}}$ is balanced by the inverse change in $\mathrm{EP}_{\mathrm{C}}$. However, the monthly variations of the performance indexes should not be neglected.

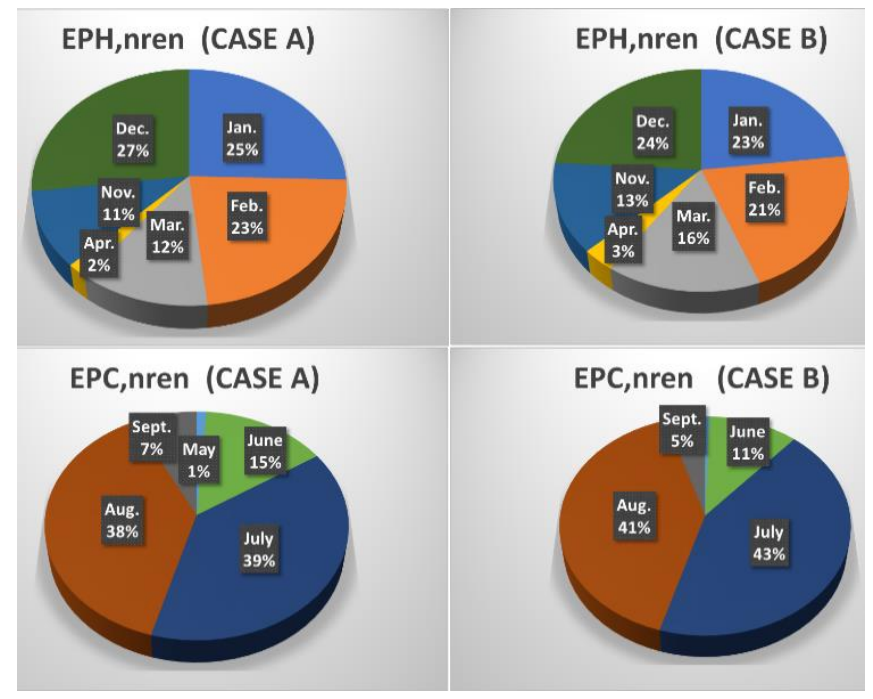

Figure 10. Monthly percentages $(\%)$ of space heating and cooling performance indexes

The graphs in Figure 10 represent the monthly percentage values of the performance indices $\mathrm{EP}_{\mathrm{H}, \text { nren }}$ and $\mathrm{EP}_{\mathrm{C} \text {,nren }}$ $\left(\mathrm{kWh} / \mathrm{m}^{2}\right)$ compared to the annual value.

The higher power installed on the third floor for artificial lighting, due to the use of fluorescent lighting sources, results in a greater contribution of heat gains in the rooms compared to case A. This translates into a decrease in energy consumed, in the heating season, and greater energy consumption for cooling during the summertime.

In case A), in the months of December and January (months with less natural light availability and higher internal lighting contributions) the percentages of $\mathrm{EP}_{\mathrm{H}, \text { nren }}$ are proportionally higher than in case B); while in the months of July and August, the $\mathrm{EP}_{\mathrm{C} \text {,nren }}$ values for case $\mathrm{A}$ ) are proportionally lower than those calculated for the second case.

The proposed procedure, unlike the normative approach, has therefore the merit of evaluating the influence of internal heat gains on the monthly variations of the energy performance indexes during the heating and cooling seasons.

A further validation of the proposed procedure for the evaluation of internal heat gains comes from the comparison between the actual consumption of the energy bills (Ce) and the operational consumption of the calculation model (Co). In this work, with evaluation using the normative approach, the deviation between operational and actual consumptions is greater than $5 \%$, while evaluating the internal heat gains with the proposed procedure, the deviation decreases to $2 \%$, which means a better calibration of the model. As already discussed, this very small difference is due mainly to the low installed power of the lighting system.

\subsection{Further analysis}

It should be noted that the results obtained are specific to this case study; indeed, the low power installed for the artificial lighting influences the final value of the internal heat gains. For this reason, it was decided to carry out a further analysis on a single hospital room, located on the first floor (Figure 5) and with an average illuminance of about 340 lux, obtained with Dialux Evo simulations considering an installed power of about $100 \mathrm{~W}$ (with LED luminaires).

Figure 11 shows the comparison between the monthly values of the total internal contributions calculated for a hospital room with an installed power of $100 \mathrm{~W}$ and $35 \mathrm{~W}$ respectively.

More installed power means also more internal heat gains for lighting. In both cases, the sum of the internal heat gains due to occupancy and electric appliances is about $6 \mathrm{~W} / \mathrm{m} 2$ and so the different contribution from lighting has a significant effect on the total value of internal heat gains and on its monthly variation.

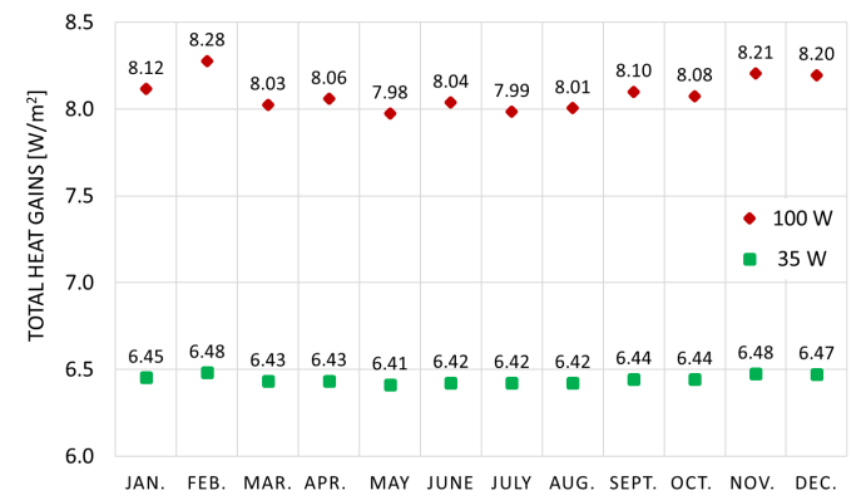

Figure 11. Monthly variation of the internal heat gains

At this stage it was analyzed the influence of several factors on the value of the LENI index (and therefore on the final value of the internal heat gains) for the hospital room with a higher power density than that of the case study.

In particular, the use of lighting control systems with various obstruction angles of shading devices were evaluated.

The control systems used for the "Brancaccio" rooms are manual with ON/OFF switch. Assuming the use of control logics based on occupancy and natural light, with the installation of infrared sensors and photodetectors, the annual energy for lighting (LENIsub) of a single patient room was calculated. The results, performed with LENICALC software, are shown in Table 7.

Table 7. LENIsub calculation

\begin{tabular}{cccc}
\hline & Occupancy & Natural light & $\begin{array}{c}\text { LENIsub } \\
{\left[\mathbf{k W h} / \mathbf{m}^{2} / \mathbf{y}\right]}\end{array}$ \\
\hline Case 1 & $\begin{array}{c}\text { MANUAL } \\
\text { ON-OFF }\end{array}$ & MANUAL & 23.42 \\
Case 2 & $\begin{array}{c}\text { MANUAL } \\
\text { ON-AUTO OFF }\end{array}$ & $\begin{array}{c}\text { VIII * } \\
\text { (EN 15193-1) }\end{array}$ & 20.87 \\
\hline
\end{tabular}

*Systems which are daylight-responsive and dim and switch off the electric lighting (“dimmed, no stand-by losses, no switch-on")

The use of a simple lighting control systems allows an energy saving, in terms of annual energy demand for lighting, of $11 \%$. As a consequence, there will be a reduction of the internal heat gains (Figure 12) because less energy will be consumed in the case of light flux regulation (dimming). A more effective control system would have led to better performance.

Finally, assuming to vary the value of the frontal obstruction angle $\theta$, the influence of shading devices on the value of the 
LENI index was evaluated. From the results obtained, it was noted that for frontal obstruction angles due to external elements there is a variation in the LENI index with an obstruction angle between 15 and $65^{\circ}$. This result is due to the method provided by the UNI EN 15193-1 Standard, according to which the incidence of obstructions on the energy consumption for artificial lighting is approximated, even though both components of light, direct and diffuse, have been considered.

The results obtained in this analysis highlight, once again, the multiplicity of factors on which the value of internal heat gains depends and the need to perform a detailed assessment to establish the energy consumption of buildings.

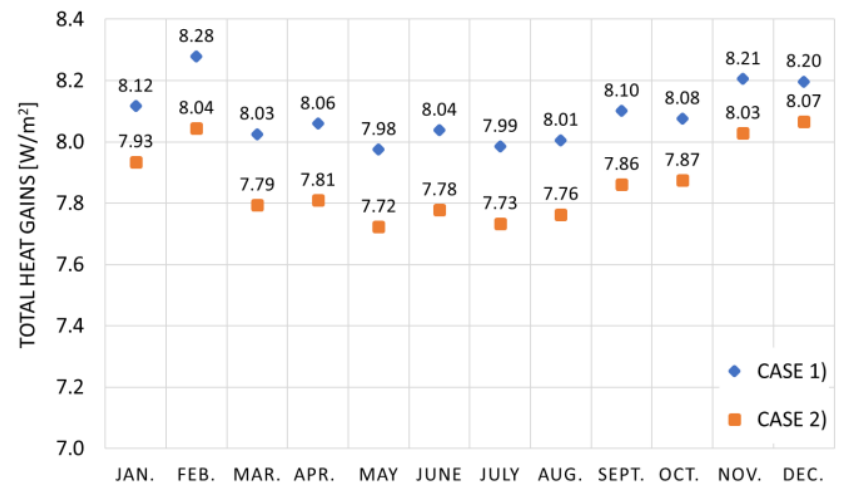

Figure 12. Monthly variation of internal heat gains

\section{CONCLUSIONS}

The main result of this study is the definition of a new procedure, based on the Lighting Energy Numeric Indicator (LENI), that takes into account the integration between natural light and artificial lighting system in the calculation of heat gains due to artificial lighting systems. The amount of the heat gains due to the artificial lighting system with the heat gains of the occupants and electrical appliances, are used to calculate the energy performance indicators of a building.

The proposed procedure has the merit of considering factors such as the installed power density, the type of lighting source/luminaire/control system, the behaviour of users, as well as the availability of natural light of the case study.

In particular, the energy performance indexes for the retirement home "Brancaccio" of Matera were compared calculating the contributions of internal heath gains, both with the standard procedure provided for by technical regulations (UNI/TS 11300) and with the proposed procedure.

In summary, the following considerations can be deduced:

- The results obtained confirm the importance of assessing the internal heat gains of artificial lighting through an energy balance on a monthly basis that considers seasonal variations due to the numerous dynamics of mutual influence between the different consumption of energy and in particular between the consumption for lighting and those for space heating and cooling.

- The monthly variation in internal heat gains for artificial lighting is less noticeable if LED sources are used than fluorescent ones; this is due to the lower installed power per unit area and the lower thermal losses in the environment.

- The monthly variations in internal heat gains are more significant with efficient control logics, such as the use of photosensors to control natural light; in this work, even with a basic control system, the monthly difference on heat internal gains of $4.4 \%$ was obtained (i.e. $3.7 \%$ with manual control).

- Underestimating or overestimating the contribution of lighting can lead to a consequent erroneous assessment of consumption for individual energy services and therefore of the overall consumption of a building. For the case study under consideration, the values of the total internal contributions calculated through the proposed procedure are lower than those assessed through the regulatory approach. As a result, an increase in the $\mathrm{EP}_{\mathrm{H}, \text { nren }}$ space heating performance index of $10.7 \%$, a decrease in the $\mathrm{EP}_{\mathrm{C} \text {,nren }}$ space cooling performance index of $8.3 \%$ and a slight increase overall $(+1.6 \%)$ the $\mathrm{EP}_{\mathrm{gl}, \mathrm{nren}}$ global performance index.

- Despite the differences found, the retirement home "Brancaccio" is in the same energy class with both approaches used: the value of the index $\mathrm{EP}_{\mathrm{gl}, \text { nren }}$ calculated with the proposed procedure is $166.12 \mathrm{kWh} / \mathrm{m}^{2} /$ year while using the regulatory approach it is worth 163.47 $\mathrm{kWh} / \mathrm{m}^{2} /$ year. However, it is important to consider the monthly changes in performance indexes. As shown in Figure 10, the higher installed power (case B) for artificial lighting causes an extra-monthly consumption of $+4 \%$ for space cooling energy-use of the rooms (mainly in the months of July and August).

The several factors on which energy consumption for artificial lighting depends, combined with their influence on the monthly variations in energy performance indexes, allows to understand how the standard use of a constant average annual value for the estimation of internal heat gains cannot best represent the energy and dynamic behavior of a building.

The authors hope that a more precise procedure (although longer and more articulated) for the calculation of internal heat gains in buildings, can soon be implemented in the procedures prescribed by the technical regulations especially for nearly zero energy buildings and boosting the available renewable energy sources (which often have a behavior strongly influenced by climatic conditions) [15].

\section{FUTURE DEVELOPMENTS}

- One of the possible future developments of this study could be the extension of the calculation of primary energy requirements related to artificial lighting in residential buildings. In this direction, the UNI/CT023/GL10 working group coordinated by ENEA is working to define the LENI values, for the different uses, to be included within the regulatory framework of the UNI/TS. With the transposition of the European Directives on energy efficiency and performance, all new buildings or buildings undergoing to important energy retrofit interventions will have to be nZEB (nearly Zero Energy Building). Among the requirements to achieve this goal [16], artificial lighting can play an important role, with particular reference to the installation of smart systems able to exploit natural light (daylighting) and reduce energy consumption for artificial lighting system.

- The study undertaken leaves room for future research since the values of heat released into the environment by lighting source-luminaire-control systems are not 
uniquely indicated in any study, being in addition subject to continuous updating. The LED technology is in fact in great development and recent improvements in terms of efficiency allow to expect ever better performance in the short and long term.

- Finally, recalling that a monthly calculation procedure was used in the assessment of energy needs, the work carried out could be expanded by adopting a dynamic time calculation model (UNI EN ISO 52016-1), in order to refine the energy balance results and to consider hourly variations of environmental parameters such as air temperature, relative humidity and velocity [17].

- Work in progress on ISO 10916; the revised standard has these objectives: 1) to define the calculation methodology for determining the hourly, monthly and annual amount of daylight entering non-residential buildings and the impact thereof on the energy demand for electric consumptions; 2) to provide the connection of the daylight supply and lighting controls to the installed power density of the electric lighting system for the overall lighting energy balance equation. The comprehensive method allows to perform the above mentioned hourly, local climate weather-based calculations with a generic facade, and sloped roof model including dynamic shading and protection of glare by daylight which are in line with hourly calculation schemes for space heating, ventilation and space cooling consumptions [17].

- In conclusion, it can be said that the regulatory frontier of nZEB buildings is now a mandatory requirement for all new private and public buildings, the importance of controlling artificial lighting, space heating and cooling systems and indoor air quality, in the comfort/energy saving equation, is recognized [18]. The next step will be to overcome and improve the concept of an ultra-highenergy, intelligent performance building. The evolution of building automation and smart building is represented by the cognitive building able to learn in predictive function the amount of information acquired from the data associated with sensors and actuators, and able to adapt to the actual needs of users [16]. For this further area of study, a working group has recently been created: UNI/CT058/GL03 coordinated by ENEA for the definition of the indicators of smart cities and communities and its connections to the scale of local and national networks and platforms to be included within the regulatory framework of the UNI/TS.

\section{ACKNOWLEDGMENT}

This work is part of larger projects initiated by ENEA, in particular:

- ENEA's LENICALC software has been developed as part of a National Research Project since 2015. In particular, the current version in the Project 1.7 "Technologies for the efficient penetration of the electric vector in the final uses" within the "Electrical System Research" Programme Agreements 19-21 between ENEA and the Ministry of Economic Development. A new Web version of the LENICALC tool is under development and will be available starting in 2022 on the PELL website [13].
- The "A COGnItive dynamic sysTem to allow buildings to learn and adapt - COGITO" project [19] is focused on the integration of Internet of Things (IoT) with dynamic cognitive systems (SDC) with the aim of improving the management of public and residential buildings with cognitive and self-developed capabilities. The goal of the project is to combine IoT technology, cognitive computing, big data, machine learning and reasoning to help people live and work better in buildings; as well as maintain and manage the building itself by providing it the capabilities to learn over time how to improve building management by programming, monitoring and control actions in advance (Industrial research and experimental development project PNR 20152020, DD n. 1735 del 13/07/2017).

\section{REFERENCES}

[1] Caldera, M., Ungaro, P., Cammarata, G., Puglisi, G. (2018). Survey-based analysis of the electrical energy demand in Italian households. Mathematical Modelling of Engineering Problems, 5(3): 217-224. https://doi.org/10.18280/mmep.050313

[2] Belussi, L., Danza, L., Meroni, I., Salamone, F., Minutoli, S., Romeo, C. (2018). Simplified tool for the energy performance assessment of residential buildings. Modelling, Measurement and Control B, 87(3): 122-128. https://doi.org/10.18280/mmc_b.870302

[3] Magrini, A., Lazzari, S., Marenco, L., Guazzi, G. (2018). Cost optimal analysis of energy refurbishment actions depending on the local climate and its variations. Mathematical Modelling of Engineering Problems, 5(3): 268-274. https://doi.org/10.18280/mmep.050321

[4] Mutani, G., Todeschi, V. (2021). GIS-based urban energy modelling and energy efficiency scenarios using the energy performance certificate database. Energy Efficiency, 14: 47. https://doi.org/10.1007/s12053-02109962-z

[5] Mutani, G., Beltramino, S., Schiavone, M. (2020). Placebased atlas for energy communities using energy performance certificates database. 2020 IEEE 3rd International Conference and Workshop in Óbuda on Electrical and Power Engineering (CANDO-EPE), pp. 179-184. https://doi.org/10.1109/CANDOEPE51100.2020.9337766

[6] Italian Standard UNI/TS 11300: Part 1, Energy performance of buildings. Part 1: Evaluation of energy need for space heating and cooling (according to ISO 13790:2007), 2014, Italian Regulatory Body UNI.

[7] Mouffok, M., Aidaoui, L., Zemmouri, N. (2019). Evaluation study of energy performance and conformity to regulations for ordinary and HEP housings: Case study based on measurements at Djelfa City, Algeria. Instrumentation Mesure Metrologie, 18(2): 171-180. https://doi.org/10.18280/i2m.180212

[8] Mukherjee, S. (2017). Simulation of daylight and artificial lighting integration and energy savings. Environmental and Earth Sciences Research Journal, 4(1): 17-22. https://doi.org/10.18280/eesrj.040104

[9] Lo Verso, V.R.M., Mutani, G., Blaso, L. (2014). Methodology to link the internal heat gains from lighting to the global consumption for the energy certification of 
buildings in Italy. Journal of Daylighting, 1(1): 56-67. https://doi.org/10.15627/jd.2014.6

[10] Danza, L., Belussi, L., Floreani, F., Meroni, I. (2018). Application of model predictive control for the optimization of thermo-hygrometric comfort and energy consumption of buildings. Instrumentation, Mesure, Métrologie, 17(3): 375-391. https://doi.org/10.3166/I2M.17.375-391

[11] EN 15193-1:2017. Energy performance of buildings Energy requirements for lighting - Part 1: Specifications, Module M9, European Standard.

[12] Guidelines for computerized calculation for the determination of LENI according to the complete calculation method of UNI EN 15193-1:2017.

[13] PELL buildings section to free download LENICAL. https://www.pell.enea.it/enea/, accessed on July $8^{\text {th }}, 2021$.

[14] Palazzoli Academy. Fondamenti di illuminotecnica. Vantaggi dell'illuminazione a LED, pp. 53.54

[15] Batov, Eugeny I., (2015). The distinctive features of "smart" buildings. Procedia Engineering, 111: 103-107. https://doi.org/10.1016/j.proeng.2015.07.061

[16] Ding, L., Chen, C. (2021). Thermal environment optimization and energy saving of residential buildings under the demand of low-carbon operation. International Journal of Heat and Technology, 39(2): 659-668. https://doi.org/10.18280/ijht.390238

[17] Genco, A., Viggiano, A., Rospi, G., Cardinale, N., Magi, V. (2015). Dynamic modeling and simulation of buildings energy performance based on different climatic conditions. International Journal of Heat and Technology, 33(4): 107-116. http://dx.doi.org/10.18280/ijht.330414

[18] Guazzi, G., Bellazzi, A., Meroni, I., Magrini, A. (2017). Refurbishment design through cost-optimal methodology: The case study of a social housing in the northern Italy. International Journal of Heat and $\begin{array}{lll}\text { Technology, } & 35(1): & \text { S336-S344 }\end{array}$ https://doi.org/10.18280/ijht.35Sp0146

[19] COGITO - A COGnItive dynamic sysTem to allOw buildings to learn and adapt. https://ict.enea.it/cogito/, accessed on July $8^{\text {th }}, 2021$.

\section{NOMENCLATURE}

\begin{tabular}{|c|c|}
\hline A & Area, $\mathrm{m}^{2}$ \\
\hline $\mathrm{c}$ & constant illuminance \\
\hline $\mathrm{C}$ & Cooling \\
\hline $\mathrm{D}$ & Daylight \\
\hline CCT & Correlated Colour Temperature, $\mathrm{K}$ \\
\hline ENEA & $\begin{array}{l}\text { Agency for New technologies, Energy and } \\
\text { Environment - Ente per le Nuove tecnologie, } \\
\text { l'Energia e l'Ambiente (in Italian) }\end{array}$ \\
\hline $\mathrm{EP}$ & Energy Performance index, $\mathrm{kWh} / \mathrm{m}^{2} /$ year \\
\hline$f_{p}$ & factor for non-renewable primary energy \\
\hline $\mathrm{F}$ & Factor \\
\hline $\mathrm{gl}$ & global \\
\hline $\mathrm{H}$ & Heating \\
\hline int & internal \\
\hline IR & Infrared \\
\hline $\mathrm{L}$ & artificial Lighting \\
\hline $\mathrm{L}_{\mathrm{v}}$ & luminance, $\mathrm{cd} \mathrm{m}^{-2}$ \\
\hline $\mathrm{L}_{\mathrm{e}}$ & radiance, $\mathrm{W} \mathrm{sr}^{-1} \mathrm{~m}^{-2}$ \\
\hline LED & Light Emitting Diode \\
\hline LENI & Lighting Energy Numerical Indicator \\
\hline NLE & Not Lighting Energy \\
\hline nren & non-renewable \\
\hline $\mathrm{O}$ & Occupancy \\
\hline $\mathrm{P}$ & radiant Power, $\mathrm{W}$ \\
\hline $\mathrm{T}$ & Transport of people or things \\
\hline UV & Ultraviolet \\
\hline $\mathrm{V}$ & Ventilation \\
\hline VRV & Variable Refrigerant Volume systems \\
\hline W & hot Water production \\
\hline
\end{tabular}

\section{Greek symbols}

$\begin{array}{ll}\phi & \text { internal heat gains, } \mathrm{Wm}^{-2} \\ \Phi & \text { luminous flux, } \mathrm{lm} \\ \Omega & \text { solid angle, } \mathrm{sr} \\ \theta & \text { (plane) angle, }{ }^{\circ}\end{array}$

